\title{
The mammalian TFIID protein is present in two functionally distinct complexes
}

\author{
H.Th. Marc Timmers and Phillip A. Sharp ${ }^{1}$ \\ Center for Cancer Research and Department of Biology, Massachusetts Institute of Technology, Cambridge, \\ Massachusetts 02139 USA
}

\begin{abstract}
The TFIID activity recognizes a TATA-box element and supports formation of an initiation complex containing RNA polymerase II. Antisera specific for the 38-kD human TFIID protein were used to determine whether this protein cofractionated with the TFID activity. Surprisingly, the TFIID activity in HeLa whole-cell extracts was resolved into two different size complexes, one of $300 \mathrm{kD}$ and one of $>700 \mathrm{kD}$. Cofractionation studies suggest that both complexes contain the $38-\mathrm{kD}$ protein; thus, this component of the large complexes is probably responsible for recognition of the TATA sequence and interaction with the other general transcription factors in formation of the initiation complex. Interestingly, in contrast to the TFIID activity characterized previously, the 300-kD form of TFIID activity, B-TFIID, does not support stimulation of transcription by factors containing acidic or glutamine-rich activating motifs. We propose that the functional and physical differences between these two forms of TFIID activity are caused by differences in the protein composition of the TFIID complexes of which the 38-kD hTFIID protein is an integral part.
\end{abstract}

[Key Words: TATA-binding protein; TFIID; in vitro transcription; general transcription factors; RNA polymerase II]

Received August 5, 1991; revised version accepted September 10, 1991.

Initiation of transcription in mammalian cells by RNA polymerase II is a complex process that requires multiple additional protein factors. These factors can be divided into two groups: distally binding transcriptional activators (for reviews, see Johnson and McKnight 1989; Mitchell and Tjian 1989) and general transcription factors (for reviews, see Wasylyk 1988; Sawadogo and Sentenac 1990). A preinitiation complex is formed over the transcription start site by the general factors and the polymerase. Both order-of-addition transcription assays (Fire et al. 1984; Reinberg et al. 1987) and gel-shift experiments (Buratowski and Sharp 1989; Maldonado et al. 1990) demonstrated that the general transcription factors (TFIIA, TFIID, TFIIB, and TFIIE/F) and the polymerase enter the preinitiation complex in a sequential way.

The general factors were first identified in extracts of HeLa cells (Matsui et al. 1980; Samuels et al. 1982; Davison et al. 1983; Reinberg and Roeder 1987; Reinberg et al. 1987) and named according to their elution profile on phosphocellulose columns (Matsui et al. 1980). The 0.6-1 $\mathrm{M} \mathrm{KCl}$ eluate (D fraction) contains the TFID activity (D-TFID) that binds to the TATA-box element, which is common to many polymerase promoters. The molecular mass estimates of the TFIID factor /or the rat liver homolog $\tau$ ) range between 140 and $1300 \mathrm{kD}$ (Samuels et al. 1982; Reinberg et al. 1987; Conaway et al. $1990,1991)$.

${ }^{1}$ Corresponding author.
Studies of the D-TFIID factor have been hampered by the difficulty of purification of this activity from cellular extracts (Nakajima et al. 1988; Maldonado et al. 1990). This problem was bypassed when it was discovered that yeast cells contain a protein that is functionally similar to the D-TFIID activity (Buratowski et al. 1988; Cavallini et al. 1988). The yeast gene encoding this TFIID activity was cloned (Hahn et al. 1989; Horikoshi et al. 1989; Schmidt et al. 1989), and the presence of conserved repeated domains in this protein allowed cloning of the human cDNA encoding the TFIID protein (Hoffmann et al. 1990; Kao et al. 1990; Peterson et al. 1990). Surprisingly, this human TFIID protein (hTFIID) has a predicted molecular mass of only $38 \mathrm{kD}$. Additionally, in contrast with the partially purified D-TFIID factor, which, in DNase I footprinting experiments protects the sequences from -45 to +35 of the adenovirus major late promoter (Sawadogo and Roeder 1985b; Nakajima et al. 1988), the recombinant $38-\mathrm{kD}$ hTFIID protein protects only a $20-\mathrm{bp}$ region around the TATA box (Hoffmann et al. 1990; Kao et al. 1990; Peterson et al. 1990). Moreover, reconstituted transcription reactions with this protein do not respond to the transcriptional activators like Spl (Peterson et al. 1990). An explanation for these differences between the partially purified endogenous D-TFIID activity and the recombinant hTFIID protein might be that in cellular extracts the $38-\mathrm{kD}$ hTFIID protein is part of a TFIID complex that also contains other proteins. Strong support for this explanation was derived recently from the 
analysis of the Drosophila TFIID activity. Purification of this factor by immunoaffinity chromatography suggests the presence of at least six additional polypeptides in the Drosophila TFIID complex (Dynlacht et al. 1991).

Using a hTFIID fusion protein, we obtained rabbit antisera specific for the hTFIID protein. These sera were used to determine whether this $38-\mathrm{kD}$ hTFIID protein cofractionates with the TFIID activity, as the latter was defined only by in vitro transcription assays. The $38-\mathrm{kD}$ hTFIID protein was found in the previously characterized D-TFIID fraction, the high-salt eluate of the phosphocellulose column; but, surprisingly, the majority of this protein was present in the $40-350 \mathrm{mM} \mathrm{KCl}$ eluate of this column. The hTFID-containing complex in this fraction (B-TFIID) was purified further. The activity of B-TFIID was analyzed in reconstituted transcription assays and compared with the TFIID activity in the D fraction and to the recombinant $38-\mathrm{kD}$ hTFIID protein.

\section{Results}

The 38-kD hTFIID protein from HeLa cells chromatographs in both the phosphocellulose $B$ and $D$ fractions

To investigate whether the $38-\mathrm{kD}$ hTFIID polypeptide cofractionates with TFIID activity (as determined previously in transcription assays), antisera specific for the 38-kD hTFIID protein were developed. Briefly, these antisera were obtained by immunizing rabbits with a pro- tein consisting of the first 139 amino acids of the hTFIID protein fused to glutathione $S$-transferase of Schistosoma japonicum. Thus, the sera are directed against the nonconserved amino terminus of the hTFIID protein. All three rabbits responded to this immunogen, as evidenced by a specific ELISA assay, and the antiserum with the highest titer was selected for immunoblot experiments. Because chromatography on phosphocellulose is the first step in a standard fractionation of the general transcription factors, the four fractions $A, B, C$, and D, were analyzed by immunoblotting with an affinity-purified hTFIID antiserum. As anticipated, the TFIID activity, as defined in reconstituted transcription experiments, fractionated into the $0.6-1 \mathrm{M} \mathrm{KCl}$ fraction $\mathrm{D}$ (data not shown; Samuels et al. 1982; Reinberg et al. 1987). Figure 1A shows that this D fraction contains the hTFIID protein but that the protein is also present in the $\mathrm{B}$ fraction $(0.04-0.35 \mathrm{M} \mathrm{KCl})$. Approximately $75 \%$ of the $38-\mathrm{kD}$ hTFIID protein present in a HeLa whole-cell extract chromatographs in the B fraction (data not shown). Five independent phosphocellulose preparations of HeLa whole-cell extracts were analyzed, and in all cases the hTFIID protein fractionated as stated above. The hTFIID polypeptide has the apparent mobility in SDS-polyacrylamide gels of a $45-\mathrm{kD}$ protein while its predicted molecular mass is $38 \mathrm{kD}$. In this paper we will refer to this hTFID protein according to its predicted molecular mass.

Approximately $50 \%$ of the total protein from a wholecell extract elutes in the B fraction (Samuels et al. 1982; M. Timmers and P. Sharp, unpubl.). To analyze whether

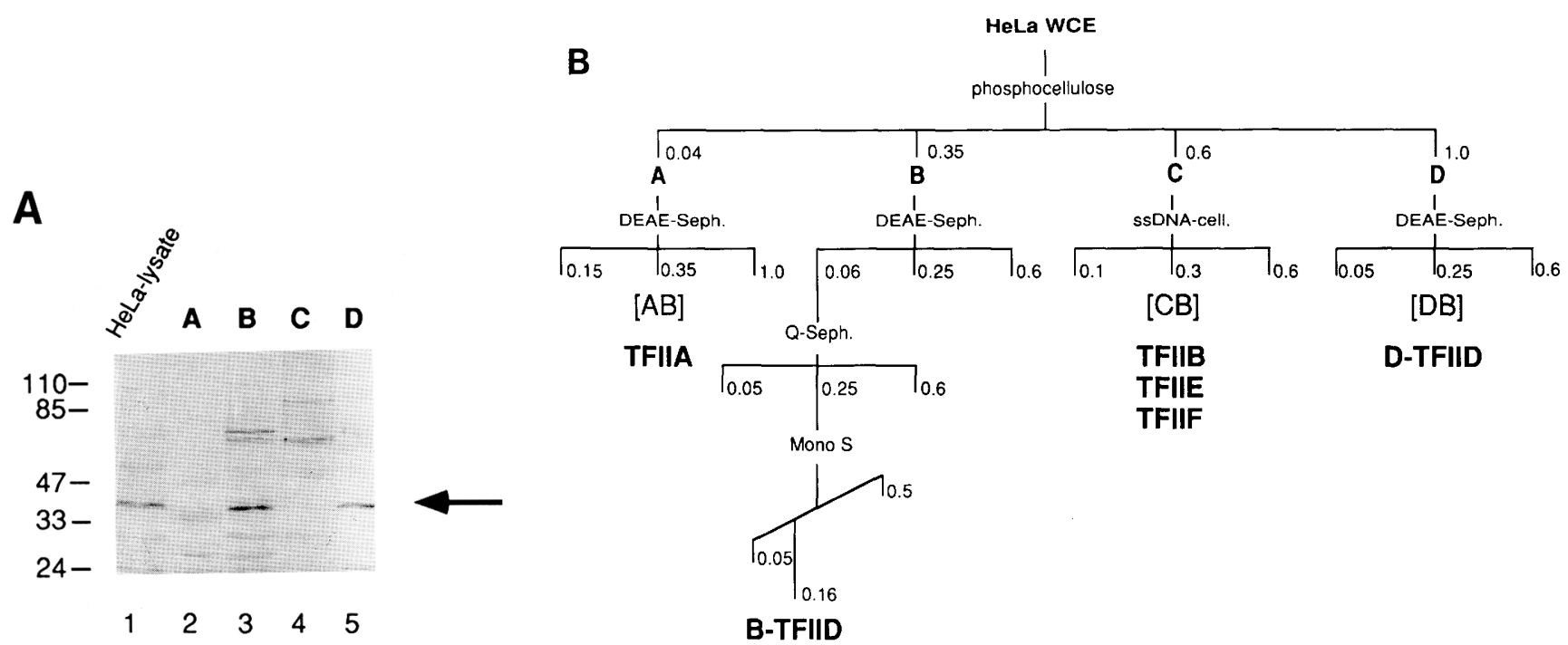

Figure 1. The $38-\mathrm{kD}$ hTFIID protein is present in two different phosphocellulose fractions. $|A|$ Immunoblot analysis of the different fractions from a phosphocellulose column. A HeLa whole-cell extract was fractionated on a phosphocellulose matrix and either 100 $\mu \mathrm{g}$ (lanes 1-4) or $50 \mu \mathrm{g}$ (lane 5) of protein from the indicated fractions was analyzed with affinity-purified antiserum specific for the hTFIID protein. The positions of comigrated prestained markers are indicated at left by their molecular mass (in $\mathrm{kD})$. The $45-\mathrm{kD}$ band indicated by the arrow represents the hTFIID protein as evidenced by comigration with bacterially expressed hTFIID (data not shown). The other protein bands stained by the antiserum were also present when preimmune serum was used and thus result from nonspecific background staining. $(B)$ Fractionation scheme for the different general transcription factors and for B-TFIID from solubilized HeLa cell extracts. The $[\mathrm{AB}]$ fraction contains TFIIA as indicated, $[\mathrm{CB}]$ provides TFIIB/E/F, and $[\mathrm{DB}]$ provides the previously characterized high-salt TFIID activity indicated as D-TFIID. 
the 38-kD hTFIID protein present in this fraction has transcriptional activity it was purified further over ion exchange matrices (as outlined in Fig. 1B) with the immunoblot assay to follow its fractionation. The chromatographic fractions were assayed for TFIID activity in a reconstituted transcription reaction with fractions [AB] and $[\mathrm{CB}]$ providing the other general transcription factors (Fig. 1B) and purified RNA polymerase II. The template contained the basal major late promoter of adenovirus. TFIID activity was detected in fractions derived from the B fraction after chromatography on the second column (data not shown). The immunoblot and transcriptional analyses of the fractions from the fourth column (Mono $S$ ) in the purification protocol are shown in Figure 2. The hTFIID protein, as detected by immunoblotting (Fig. 2A), cofractionated with the transcriptional activity in the TFIID-dependent assay (Fig. 2B). This argues strongly that the 38-kD hTFIID protein present in the phosphocellulose $B$ fraction is transcriptionally active. We propose to name this TFIID activity B-TFIID to distinguish it from the traditional form present in the phosphocellulose $\mathrm{D}$ fraction (D-TFIID). Fractions 26-33 were pooled, dialyzed, and used in the subsequent experiments as the source of B-TFIID.
Characterization of the B-TFIID activity in the basal transcription reaction

The dependence of the B-TFIID activity on the other general factors to generate basal transcription was analyzed in Figure 3. Chromatographic fractions were omitted from the transcription mixture as indicated. Transcription with B-TFIID was only partially dependent on TFIIA (about fivefold) but was totally dependent on the other protein fractions. The previously characterized TFID activity (D-TFID) from the phosphocellulose D fraction (Samuels et al. 1982) was included for comparison and has a similar dependence on the other general factors as B-TFIID. The TFIIB/E/F-containing fraction was separated by chromatography on DEAE-Sepharose into fractions containing the TFIIB or the TFIIE/F activity. The basal transcription reaction with the B-TFIID activity required the presence of both of these activities (M. Timmers, J. Parvin, and P. Sharp, unpubl.).

The transcriptional efficiencies of the $38-\mathrm{kD}$ hTFIID protein in the B-TFIID and D-TFIID fractions were analyzed by comparing the intensity of staining in a hTFIID immunoblot with the level of stimulation of the basal transcription reaction (Fig. 4). Basal transcription with

A

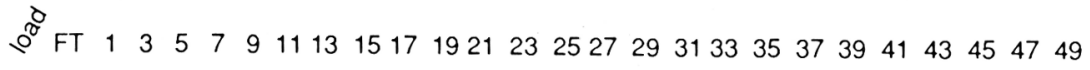

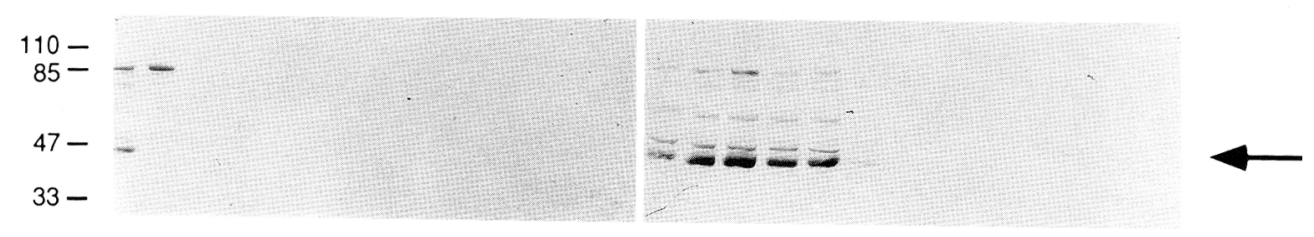

B

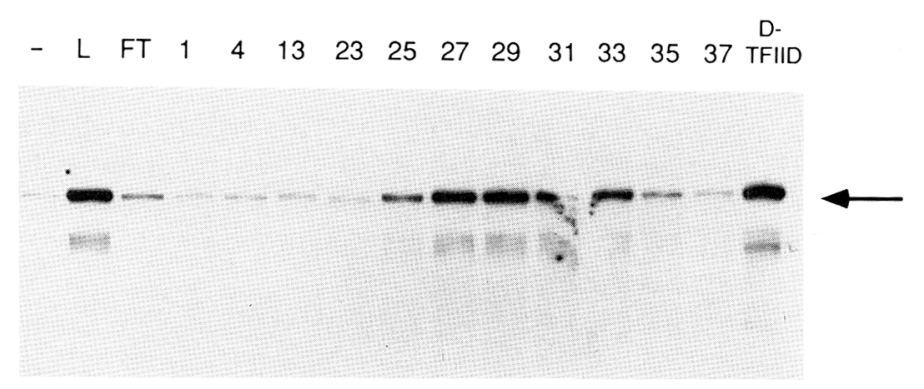

Figure 2. Fractions containing the 38-kD hTFIID protein from the phosphocellulose B fraction stimulate the basal transcription reaction. (A) Immunoblot analysis of the Mono S column fractions with antisenum specific for hTFIID. Thirty microliters of every other fraction was precipitated by 2 volumes of cold acetone, resuspended in sample buffer, and processed for immunoblot analysis with a rabbit antiserum specific for hTFIID. Positions of comigrated prestained markers are indicated by their molecular mass (in kD). The arrow indicates the hTFIID polypeptide. (B) Transcriptional analysis of Mono S fractions. Three microliters of the load (L) and flowthrough (FT) or $1 \mu \mathrm{l}$ of the eluted fractions was adjusted to buffer $\mathrm{A} / 100 \mathrm{mM} \mathrm{KCl}$ and analyzed in a TFIID-dependent transcription reaction with pML $\left(\mathrm{C}_{2} \mathrm{AT}\right) 19 \Delta-51$ as the template (Sawadogo and Roeder 1985a). This plasmid carries a 380-bp guanosine-less cassette under control of the adenovirus basal major late promoter $(-53 /+10)$. Reactions analyzed in lanes labeled - or D-TFIID received, respectively, control buffer and $1.5 \mu \mathrm{l}$ of [DB]. The arrow indicates the correctly initiated RNA product. Both the 38-kD hTFIID protein and the TFIID activity peak in fractions $27-29$, which correspond to $120-160 \mathrm{mM} \mathrm{KCl}$. 

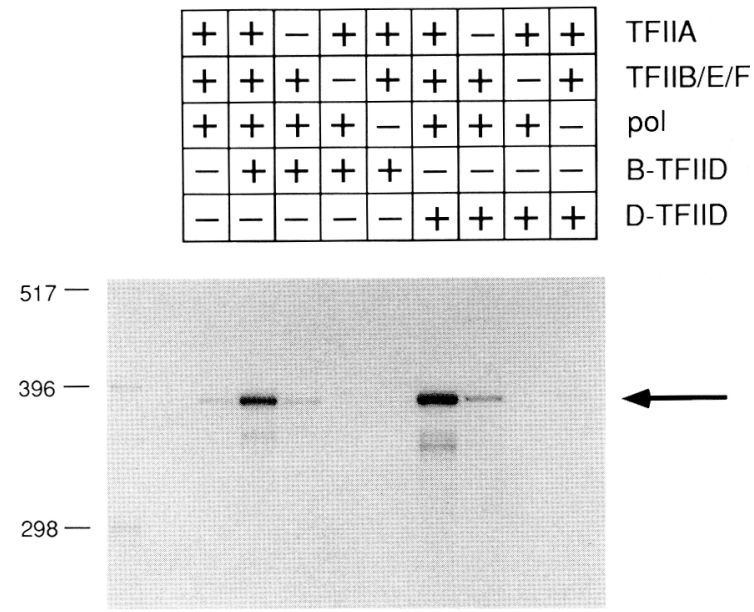

$\begin{array}{llllllllll}M & 1 & 2 & 3 & 4 & 5 & 6 & 7 & 8 & 9\end{array}$

Figure 3. Transcription with the B-TFIID fraction is dependent on the same general transcription factors as transcription with the D-TFIID fraction ([DB]). Different protein fractions (see Fig. 1B) containing the general factors were omitted as indicated from the standard TFIID-dependent transcription reaction using pML $\left(\mathrm{C}_{2} \mathrm{AT}\right.$ ) 194-51 (Sawadogo and Roeder 1985a) as template. Correctly initiated RNA products are 380 nucleotides in length and are indicated by the arrow. Three microliters of the B-TFIID fraction (pooled Mono $S$ fractions $26-33$ ) and $2 \mu$ lof the D-TFIID fraction were used. Lane $M$ contains pAT153 DNA digested with HinfI and end-labeled with ${ }^{35}$ S-labeled dATP by Klenow fragment. The lengths of the DNA fragments are indicated at left. Reactions were processed as described in Materials and methods. Quantitation of the RNA products indicates that omission of TFIIA ([AB]) with B-TFIID (lane 3) or D-TFIID (lane 7) results in a four- to fivefold decrease in transcription. In the absence of either TFIIB/E/F/ ([CB]) (lanes 4,8 ) or polymerase II (lanes 5,9 ) transcription decreases to barely detectable levels (at least a 16 -fold reduction).

the D-TFIID fraction was approximately twofold more efficient per unit of the $38-\mathrm{kD}$ polypeptide than transcription with the B-TFIID fraction and fourfold more efficient when compared to the recombinant hTFIID protein (rhTFIID). In Figure 4A transcription with B-TFIID reached a plateau when $>4 \mu \mathrm{l}$ was added, but further experiments have shown that this effect was the result of an inhibition by higher concentrations of $\mathrm{KCl}$ (data not shown; Fig. 5). Taken together, these results suggest that the level of basal transcription is determined primarily by the amount of the $38-\mathrm{kD}$ hTFIID protein in the two cellular fractions.

In the transcriptional analysis of the different TFIID preparations we noticed that increasing the $\mathrm{KCl}$ concentration in the reaction suppressed the activity of the B-TFIID fraction dramatically. Therefore, transcription reactions were reconstituted with either B-TFIID, D-TFIID, or rhTFIID at different concentrations of $\mathrm{KCl}$ (Fig. 5). Transcription with the B-TFIID fraction was partially inhibited at $90 \mathrm{~mm}$ and became undetectable at 120 mM KCl. Transcription with either the D-TFIID or rhTFIID fractions increased slightly from 30 to $90 \mathrm{mM}$
$\mathrm{KCl}$ and was only partially inhibited at $120 \mathrm{~mm}$. This sensitivity of the D-TFIID fraction is in complete agreement with data published previously (Samuels et al. 1982). The $\mathrm{KCl}$ concentration that yielded half-maximal transcription was $75 \mathrm{~mm}$ for B-TFIID and $105 \mathrm{~mm}$ for D-TFIID or rhTFIID (Fig. 5; data not shown). These differences suggest that either the interaction with DNA of the 38 -kD hTFIID-containing B-TFIID factor is less stable than the D-TFIID/DNA complex or that the interaction(s) of the B-TFIID activity with the other general factors is more sensitive to ionic strength than the equivalent interaction(s) with the D-TFIID factor.

The transcription initiation reaction can be divided into distinct steps (Davison et al. 1983; Fire et al. 1984; Reinberg et al. 1987a; Buratowski et al. 1989). The first step is a stable association of the TFIID/TFIIA complex with the TATA sequence element of the promoter. This complex apparently has a low dissociation rate, because formation of this complex during a preincubation sequesters limiting TFIID/TFIIA activity so that a subsequently added template is excluded from transcription (Fire et al. 1984; Van Dyke et al. 1989). The B-TFIID activity was tested in a template-exclusion experiment by using templates containing identical basal major late promoters upstream of a guanosine-less cassette of either 380 or 210 bp (Fig. 6). While the D-TFIID activity gave the typical exclusion pattern following a 20 -min preincubation, in the transcription reactions with the B-TFIID factor both templates were equally transcribed whether or not they were present during preincubation. This indicates that the TFIID activity in the B-TFIID fraction exchanged freely between the two templates. Because the nucleotide mixture was added $\sim 60 \mathrm{sec}$ after addition of the second template, the B-TFIID/TFIIA/DNA complex must have a high dissociation rate. A longer preincubation (30 or $40 \mathrm{~min}$ ) gave the same results (data not shown).

The results of both the $\mathrm{KCl}$ titration and the template commitment assay support the notion that interaction with the basal major late promoter of the 38 -kD hTFIDcontaining complex in the B-TFIID fraction is less stable than that of the $38-\mathrm{kD}$ hTFIID-containing complex in the D-TFIID fraction. This notion is also supported by the failure to observe binding of the B-TFIID factor to a DNA fragment consisting of the basal major late promoter under standard gel shift conditions /data not shown).

\section{Transcription with the B-TFIID activity is not responsive to transcriptional activators}

An important feature of the D-TFIID activity is that it can support stimulation of transcription by a variety of transcriptional activators. In contrast, reactions reconstituted with the recombinant 38 -kD hTFIID protein were found to be unresponsive to transcriptional activators (Peterson et al. 1990). These observations led to the hypothesis that stimulation by activators required coactivators that needed to be present in the partially purified D-TFIID fraction. We tested whether transcription with 

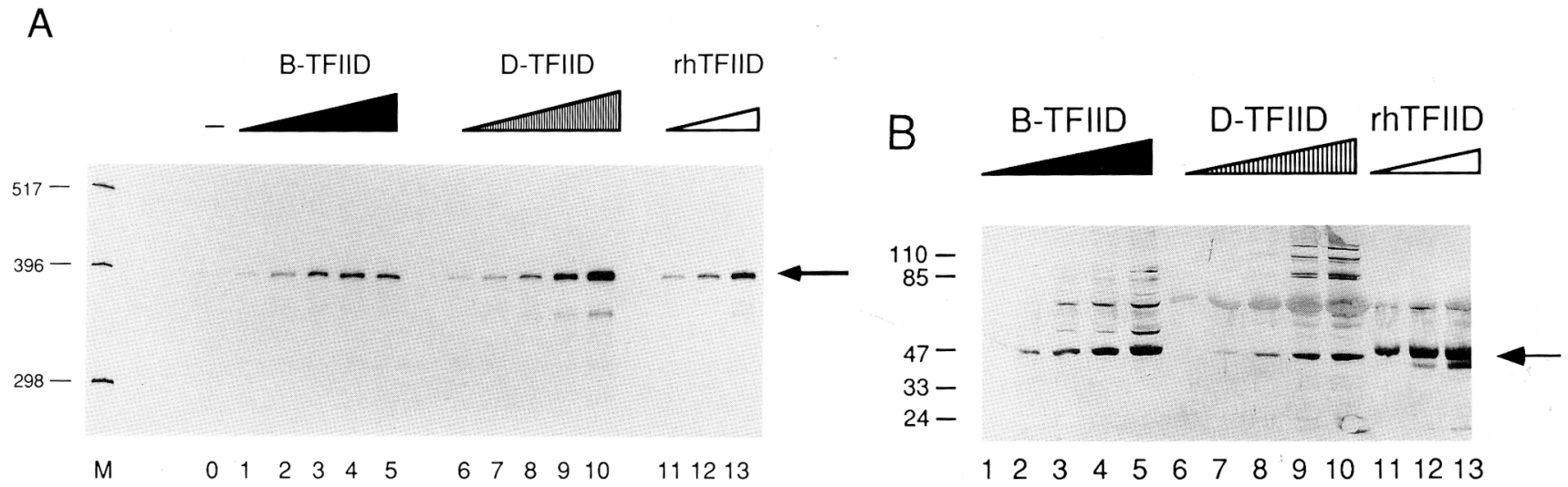

Figure 4. Transcriptional efficiency of the B-TFIID, D-TFIID, or rhTFIID fractions are comparable. (A) Standard TFIID-dependent transcription assays were performed as described in the legend to Fig. 3 with increasing volumes of B-TFIID, D-TFIID, or rhTFIID. In the reaction of lane 0 only control buffer was added. Lanes $1-5$ received $0.5,1,2,4$, or $8 \mu$ l of B-TFIID, respectively. In lanes $6-10,0.5$, $1,2,4$, or $8 \mu \mathrm{l}$, respectively, of the D-TFIID fraction $[\mathrm{DB}]$ was added. Lanes $11-13$ received $0.5,1$, or $2 \mu$ l of the recombinant hTFIID protein fraction (labeled rhTFIID). Lane $M$ contains comigrated marker fragments of the indicated lengths. Quantitation of the RNA products indicates that identical volumes of B-TFIID and D-TFIID support a similar level of the basal transcription reaction except for lane 5 (see text). Transcription levels with rhTFID were twofold higher than with the corresponding volumes of B-TFIID or D-TFIID. $(B)$ Immunoblot analysis of increasing volumes of the TFIID-containing fractions using antiserum specific for hTFIID. Positions of comigrated protein markers are indicated at left. The lanes contained the same volumes as the corresponding lanes of $A$. We estimated that staining of the B-TFIID fraction was about twice as intense as staining of the same volume of the D-TFIID preparation. The rhTFIID fraction stained four- to eightfold more intensely than the D-TFIID fraction. The difference in mobility of the rhTFIID (lanes $11-13$ ) and the $38-\mathrm{kD}$ hTFIID protein (lanes 1-10) is probably the result of the large difference in the amount of protein applied to the gel.

the B-TFIID activity could also support stimulated transcription. The reaction mixture included a test template, which has binding sites for activators fused to the basal major late promoter and directs synthesis of a 380 -nucleotide transcript, and the $\mathrm{p} \Delta \mathrm{ML}\left(\mathrm{C}_{2} \mathrm{AT}\right) 200$ template as an internal control, which carries only the basal major late promoter and yields a 210-nucleotide transcript.

Similar amounts of basal transcription activity of either B-TFIID-, D- TFIID-, or rhTFIID-containing fractions were assayed in the presence of an excess amount of partially purified major late transcription factor (MLTF) also known as upstream stimulatory factor (USF). As expected from data published previously, transcription with the bacterially expressed hTFID protein (rhTFIID) was not stimulated at all by MLTF/USF. Transcription in the reaction containing D-TFIID was stimulated almost sevenfold by the addition of MLTF/USF, whereas transcription in the reaction with B-TFIID was induced only threefold. Over multiple experiments MLTF/USF stimulated transcription with B-TFIID between two- and threefold but never more than threefold. In these reactions TFIID was the only limiting activity as determined by titrations (data not shown). Similar results were obtained when these assays were performed with different amounts of MLTF/USF or TFID activity (data not shown).

Three different classes of transcription-activating motifs have been identified by deletion analysis of transcriptional activators and by fusion of activator domains to sequence-specific DNA-binding domains. These motifs are either rich in negative charge, glutamine, or proline residues (for review, see Mitchell and Tjian 1989). It is not clear to which class the transcriptional activator MLTF/USF belongs, as its transcription-activating motif has not been analyzed. The existence of these different classes suggests the possibility that the two forms of TFIID might respond differently depending on the transcriptional activator. To test this possibility, stimulation

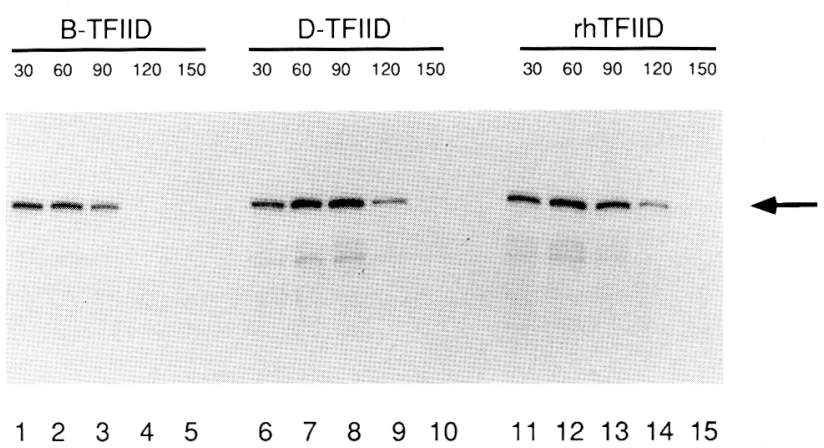

Figure 5. Transcription with the B-TFIID fraction is more sensitive to $\mathrm{KCl}$ than transcription with D-TFIID- or rhTFIID-containing fractions. Standard transcription reactions containing pML $\left(\mathrm{C}_{2} \mathrm{AT}\right) 19 \Delta-5 \mathrm{l}$ as template were reconstituted with $3.75 \mu \mathrm{l}$ of B-TFIID (lanes 1-5), $2.5 \mu$ l of D-TFIID (lanes 6-10), or $1.5 \mu \mathrm{l}$ of rhTFIID (lanes 11-15). The final $\mathrm{KCl}$ concentration in the reaction is indicated above the lanes (in $\mathrm{mm}$ ). The RNA products were processed and quantitated. The relative transcription levels with the B-TFIID fraction for the increasing salt concentrations were $100,92,63,4$, and 3 /expressed as the percentage of the maximal level); transcription levels with D-TFIID were $55,94,100,31$, and 5; levels with rhTFIID were $73,100,75,30$, and 6 . 


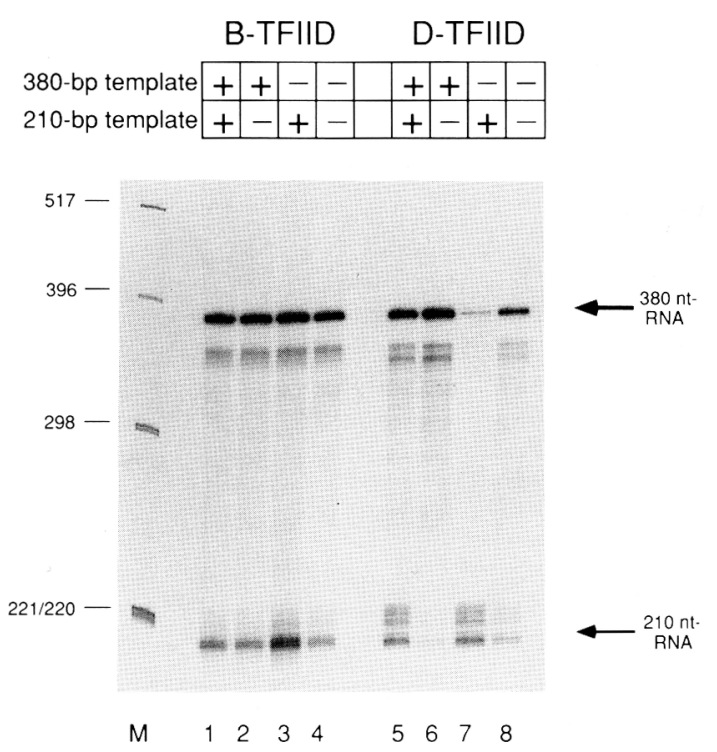

Figure 6. Preincubation of B-TFIID and DNA template does not result in template commitment. B-TFIID $(3.75 \mu l)$ or D-TFIID $(2.5 \mu \mathrm{I})$ was preincubated for 20 min under transcription conditions in a 10- $\mu$ l volume with the standard amount of the TFIIA fraction $[A B]$ and with $200 \mathrm{ng}$ of pML( $\left.\mathrm{C}_{2} \mathrm{AT}\right) 19 \Delta-51$ (380-nucleotide template) or $\left.\mathrm{p} \Delta \mathrm{ML} / \mathrm{C}_{2} \mathrm{AT}\right) 200$ (210-nucleotide template) as indicated above the lanes. Their respective RNA products are indicated by arrows at right. After this incubation the other transcription factors, the missing templates, and the nucleotide mix were added at 1 -min intervals. Transcription reactions were incubated and processed further as in standard experiments. Lane $M$ contains comigrated DNA marker fragments of the indicated lengths.

by different activators was analyzed in reactions reconstituted with either B-TFIID, D-TFIID, or rhTFIID. The acidic transcriptional activator GAL4-AH contains a negatively charged amphipathic helix fused to the DNAbinding domain of the yeast GAL4 protein. It has been shown that this GAL4-AH protein stimulates transcription efficiently in vitro both in crude nuclear extracts and in reactions reconstituted with partially purified factors (Lin and Green 1991; Workman et al. 1991). Thus, it was not surprising that GAL4-AH induced transcription in a reaction reconstituted with the D-TFIID factor by approximately fivefold (Fig. 7B). Interestingly, reactions reconstituted with either B-TFID or rhTFIID did not respond to GAL4-AH. The transcription factor Spl contains a glutamine-rich transcription-activating motif. When the different TFIID activities were assayed for stimulation by $\mathrm{Sp} 1$, only the reaction containing D-TFIID responded (Fig. 7C). As a control for endogenous Spl, transcription was assayed with templates containing the Sp1-binding sites but not the Spl-factor /lanes 5-8), and the results show that the general factor preparations were not contaminated with $\mathrm{Sp} 1$ activity. Together, these results show that reactions reconstituted with B-TFIID do not respond to the transcriptional activators GAL-AH or $\mathrm{Spl}$ and respond only weakly to MLTF/USF. This suggests that there are fundamental differences in the initiation processes directed by B-TFIID and D-TFIID.

\section{The B-TFIID and D-TFID factors are in physically distinct complexes}

Previous experiments suggested that the $38-\mathrm{kD}$ hTFIID protein from the phosphocellulose $\mathrm{D}$ fraction might be part of a large protein complex. When the D-TFIID activity was characterized by sedimentation in sucrose gradients, it peaked at $\sim 17 \mathrm{~S}$, which corresponds to a molecular mass of $750 \mathrm{kD}$ /Samuels et al. 1982; Conaway et al. 1991). Analysis by gel filtration yielded contradictory results. Both 120-140 kD (Reinberg et al. 1987a) and $1300 \mathrm{kD}$ (Conaway et al. 1990) have been reported as molecular masses. Differences in the nature of complexes containing the $38-\mathrm{kD}$ hTFIID protein might explain the differences in the responses of reactions reconstituted with D-TFIID, B-TFIID, and rhTFIID to transcriptional activators (e.g., see Fig. 7; Peterson et al. 1990; Pugh and Tiian 1990).

The molecular mass of B-TFIID was analyzed by gel filtration on a Superose 12 FPLC column. The phosphocellulose B fraction was used as the source for B-TFIID. Fractions were collected and analyzed by immunoblot with a crude hTFIID antiserum (Fig. 8A). The $38-\mathrm{kD}$ hTFIID protein eluted with an apparent molecular mass of $\sim 300 \mathrm{kD}$. This indicates that B-TFIID is a complex of $300 \mathrm{kD}$. Consistent with this proposal, when the B-TFIID activity in the pooled Mono $S$ fractions was fractionated similarly on a preparative gel filtration column (Superdex 200) the transcriptional activity chromatographed as a species of $300 \mathrm{kD}$ (data not shown). These data suggest that the TFID activity in the $B$ fraction is in a complex of a different size than D-TFIID factor. To verify this, the molecular mass of D-TFIID was determined by Superose 12 gel filtration under identical conditions as B-TFIID. In agreement with the previous sedimentation analyses (Samuels et al. 1982; Conaway et al. $1991)$ the $38-\mathrm{kD}$ hTFIID protein present in D-TFIID eluted as a complex of $>700 \mathrm{kD}$ (Fig. 8B). To test whether the two forms of complexes containing the 38$\mathrm{kD}$ hTFIID protein could also be detected prior to phosphocellulose chromatography, a standard HeLa wholecell extract was fractionated by Superose 12 gel filtration and analyzed by immunoblotting with the crude hTFIID antiserum (Fig. $8 \mathrm{C}$ ). These results indicate that the majority $(>75 \%$ ) of the $38-\mathrm{kD}$ hTFIID protein present in the total extract was in the $300-\mathrm{kD}$ complex, but the $>700$ $\mathrm{kD}$ complex was also detected. The $>700-\mathrm{kD}$ form of TFIID probably fractionates on a phosphocellulose matrix in the $\mathrm{D}$ fraction, whereas the $300-\mathrm{kD}$ form elutes in the B fraction. Surprisingly, no free $38-\mathrm{kD}$ hTFIID protein could be detected in the analysis of the total extract. Essentially all of the $38-\mathrm{kD}$ hTFIID protein is found in the B-TFIID or in the D-TFIID complex.

\section{Discussion}

The human TFIID protein is encoded by a specific gene 
A

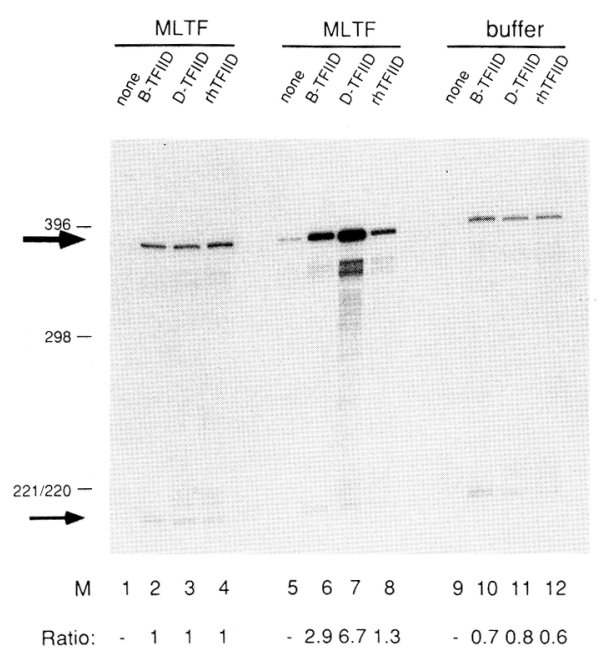

B

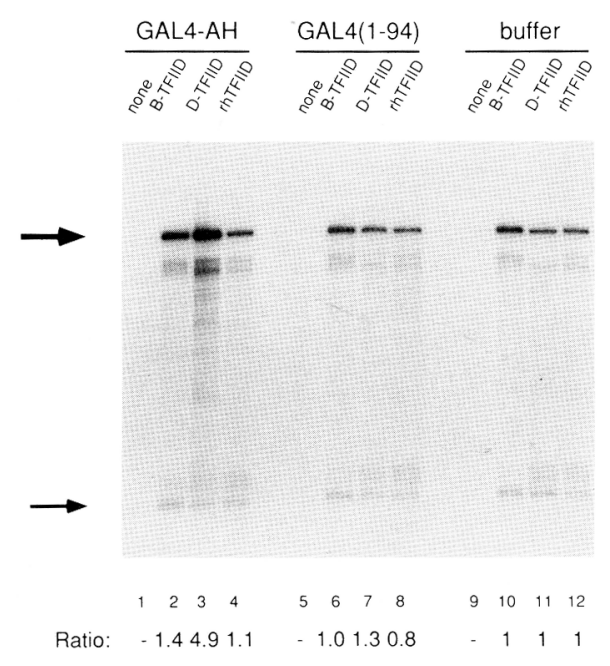

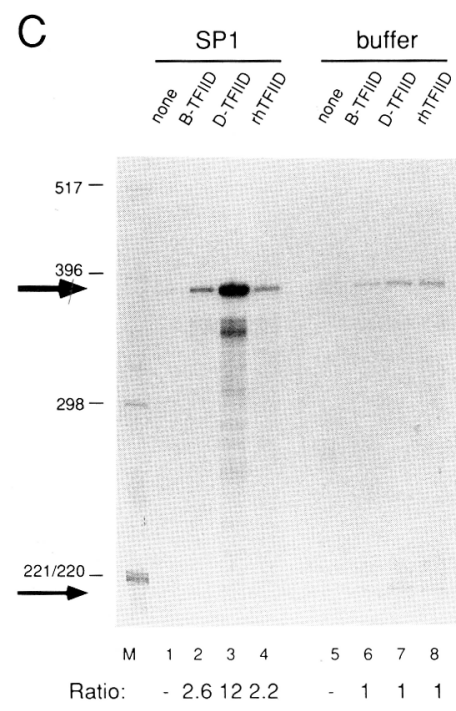

Figure 7. Reactions reconstituted with B-TFIID do not respond to transcriptional activators. $(A)$ Standard transcription reactions were performed in the presence of saturating amounts of MLTF, which was partially purified from calf brain extracts (lanes 1-8) or control buffer (lanes 9-12). All transcription mixtures contained $100 \mathrm{ng}$ of $\mathrm{p} \Delta \mathrm{ML}\left(\mathrm{C}_{2} \mathrm{AT}\right) 200$. Template $\mathrm{pML}\left(\mathrm{C}_{2} \mathrm{AT}\right) 19 \Delta-51$ (100 ng/reaction), which lacks the MLTF-binding site, was included in lanes 1-4. The other reactions (lanes 5-12) contained $100 \mathrm{ng}$ of pML112(C $\mathrm{C}_{2} \mathrm{AT}$ ), which carries the major late promoter from -112 to +10 and contains the MLTF-binding site (see Materials and methods). Three microliters of B-TFIID (lanes 2,6,10), $2 \mu$ l of D-TFID (lanes 3,7,11), or $1.25 \mu$ l of rhTFID (lanes 4,8,12) was used. Lanes labeled none $(1,5,9)$ received control buffer. The stimulation ratio was calculated by dividing $R_{380} s / R_{210} s$ by $R_{380} u / R_{210} u$. $R_{380} s$ and $R_{210} s$ represent, respectively, the radioactivity in the 380- and 210-nucleotide transcripts in the presence of the transcriptional activator. $R_{380} u$ and $R_{210}$ u represent, respectively, the radioactivity in the 380- and 210-nucleotide transcripts in the absence of the transcripional activator. The reactions of lanes $2-4$ were used to determine $R_{380} u / R_{210} u$. Positions of comigrated markers are indicated at left. The thick arrow indicates the RNA product derived from the test template; the thin arrow indicates the RNA product from the shorter control template. $(B)$ Transcriptional response to the acidic activator GAL4-AH. The different TFIID preparations (identical amounts as in $A$ ) were added as indicated above the lanes. Reactions were performed by using $100 \mathrm{ng}$ of p6GALML(C $\mathrm{C}_{2} \mathrm{AT}$ ) (see Materials and methods) in addition to $\mathrm{p} \Delta \mathrm{ML}\left(\mathrm{C}_{2} \mathrm{AT}\right) 200$, which served as the internal control. One picomole of GAL4-AH or GAL4(1-94) protein (kind gifts of J. Workman and R.E. Kingston) was added as indicated. The reactions of lanes 10-12 were used to determine $R_{380} u / R_{210} u$, and stimulation ratios were calculated as in $A$. $(C)$ Transcriptional response to the glutamine-rich activator Spl. Transcription reactions were performed with $100 \mathrm{ng}$ of $\operatorname{pSVML}\left(\mathrm{C}_{2} \mathrm{AT}\right.$ ) (see Materials and methods) and also contained an equivalent amount of $\mathrm{p} \Delta \mathrm{ML}\left(\mathrm{C}_{2} \mathrm{AT}\right.$ ) 200 as the internal control. Either $1 \mu \mathrm{l}$ (lanes 1-4) of affinity-purified HeLa Sp1 (Promega) or control buffer (lanes 5-8) was added as indicated. The reactions of lanes $10-12$ were used to determine $R_{380} u / R_{210} u$, and stimulation ratios were calculated as in $A$. Lane $M$ contains comigrated DNA marker fragments as described in the legend to Fig. 3.

and has a molecular mass of $38 \mathrm{kD}$ (Hoffmann et al. 1990; Kao et al. 1990; Peterson et al. 1990). In contrast, the TFIID activity in whole-cell extracts from HeLa cells is found in two complexes, B-TFIID and D-TFIID, which have molecular masses of 300 and $>700 \mathrm{kD}$, respectively. Both of these complexes contain the $38-\mathrm{kD}$ hTFIID protein. Surprisingly, and in contrast to the situation in yeast cells (Buratowski et al. 1988), no TFIID protein could be detected in HeLa whole-cell extracts in the $38-\mathrm{kD}$ size range, which would correspond to the monomeric protein. This suggests that assembly of the human $38-\mathrm{kD}$ TFIID protein into large heteromeric complexes is very efficient and that when the hTFIID protein is not assembled, it is rapidly degraded. This would be reminiscent of the assembly of other multisubunit complexes like ribosomes, where individual subunit polypeptides are degraded rapidly unless incorporated into the complex.

Originally, the TFIID activity from HeLa cell extracts was defined by a biochemical complementation assay and was detected exclusively in a fraction that eluted from a negative-charge column at high concentrations of salt (Samuels et al. 1982; Reinberg et al. 1987). The fact that the 38-kD hTFIID polypeptide coelutes and copurifies with this form of TFIID acivity (D-TFIID) suggests that this $38-\mathrm{kD}$ protein is part of the D-TFIID activity. The large size of this activity $(>700 \mathrm{kD})$ indicates that the $38-\mathrm{kD}$ hTFIID polypeptide is complexed in a noncovalent but stable fashion to other components-probably proteins. It is surprising that a complex of this size can be accommodated in the initiation complex containing TFIIA, TFIIB, polymerase II, and TFIIE/F in an equivalent role as the monomeric yeast TFIID protein (yTFIID). Reactions reconstituted with $27-\mathrm{kD}$ yTFIID require this same set of general factors for initiation as the larger D-TFIID or B-TFIID complexes do. Gel mobility-shift assays combined with footprint analyses have shown that yTFIID binds the major late TATA region from -42 to -17 (Buratowski et al. 1989). The protein then makes specific contacts with the TFIIA and TFIIB factors. Sub- 


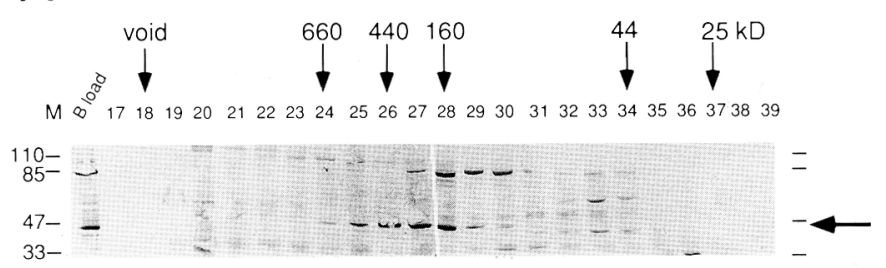

B

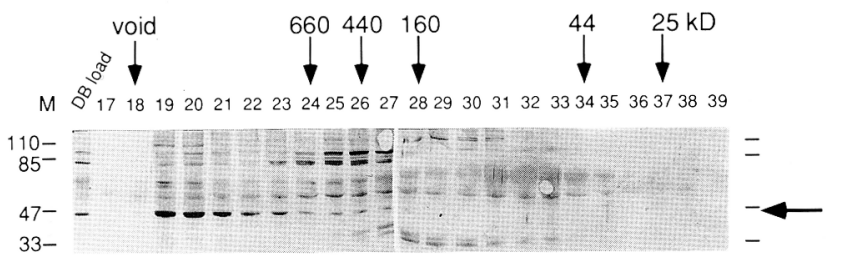

C

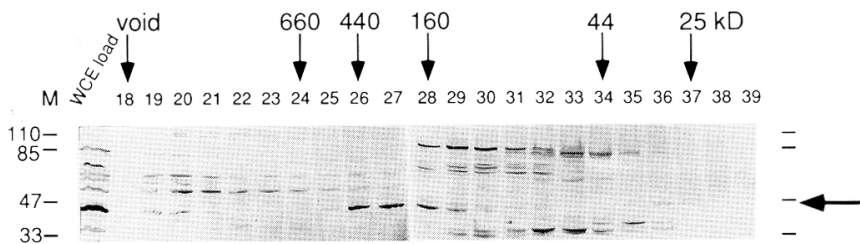

Figure 8. The $38-\mathrm{kD}$ hTFIID proteins from the phosphocellulose $\mathrm{B}$ and $\mathrm{D}$ fractions are in different size complexes. $(A) \mathrm{Gel}$ filtration and immunoblot analysis of the phosphocellulose $B$ fraction. A 200- $\mu$ l aliquot of the phosphocellulose B fraction was adjusted to the elution buffer (buffer $\mathrm{A} / 400 \mathrm{mM} \mathrm{KCl} / 0.01 \%$ Triton X-100) and loaded onto a Superose 12 column. Fourhundred microliter fractions were collected and precipitated with 2 volumes of cold acetone. Protein pellets were resuspended in sample buffer and processed for immunoblot analysis with antiserum specific for hTFIID (see Materials and methods). The arrow to the right of the blot indicates the position of the hTFIID protein. The arrows above the blot denote the fraction in which standard proteins of the indicated molecular mass fractionate under these conditions. The positions of comigrated prestained markers are indicated at left by their molecular masses (in kD). (B) Gel filtration and immunoblot analysis of D-TFIID. A [DB]-aliquot was prepared, chromatographed, and analyzed as described in $A .|C\rangle$ Gel filtration and immunoblot analysis of an HeLa whole-cell extract. A 100- $\mu$ l aliquot of extract was adjusted to elution buffer (buffer $\mathrm{A} / 500 \mathrm{~mm} \mathrm{KCl}$ ) and, subsequently, chromatographed and analyzed as in $A$. The multiple other bands detected in addition to the hTFIID protein band result from nonspecific staining by the antiserum, as they were also detected by staining with the preimmune serum. The weak band in fraction 36 does not comigrate with the band representing the $38-\mathrm{kD}$ hTFIID protein. sequently, the large polymerase II entity $1500-600 \mathrm{kD}$; for review, see Sawadogo and Sentenac 1990) binds to the promoter, and the formed complex will protect sequences from -47 to +20 . The TFIIE/F factor is then thought to bind downstream of the polymerase from +20 to +30 (Buratowski et al. 1989). The 38-kD hTFIID component of the large D-TFIID complex probably makes the same contacts with TFIIA, TFIIB, and polymerase II as the free $38-\mathrm{kD}$ rhTFIID protein in specifying the initiation complex. Thus, to accommodate the interactions with these factors, several surfaces of this small protein must be exposed in the large D-TFIID complex. This raises the question of how the other components of the large D-TFIID complex can be distributed so that they do not interfere with the binding of the other general factors and polymerase. It is possible that they are extended along the opposite face of the template from the polymerase. This would be consistent with previous footprint analyses indicating that a component in the D-TFIID activity protected sequences from -45 to +35 (Sawadogo and Roeder 1985b; Nakajima et al. 1988) and with the recently proposed structure for RNA polymerase II suggesting that this enzyme may contact primarily only one face of the DNA template (Darst et al. 1991).

The novel form of TFIID activity described here, B-TFIID, eluted from a negatively charged matrix in the low-salt fraction B. Approximately $75 \%$ of the $38-\mathrm{kD}$ hTFIID protein in the extract partitioned in this fraction. TFIID transcriptional activity could not be detected in the initial fraction but became apparent upon further purification and concentration. Again, the $38-\mathrm{kD}$ hTFIID protein copurified with the transcriptional activity in this fraction, suggesting that this $38-\mathrm{kD}$ protein is part of the B-TFIID activity that can support the basal transcription reaction. As was found for D-TFIID, the B-TFIID transcriptional activity depends on the other general transcription factors-TFIIA, TFIIB, TFIIE/F, and polymerase II. The B-TFIID activity also depends on recognition of the TATA element of the promoter ( $M$. Timmers, J. Parvin, and P. Sharp, unpubl.). It should be noted that unlike the even larger D-TFIID factor (Sawadogo and Sentenac 1990|, the B-TFIID complex is reasonably stable during purification. Thus, the proteins constituting this $300-\mathrm{kD}$ complex are probably tightly associated.

When the B-TFIID and D-TFIID activities were compared for efficiency to support the basal transcription reaction, there was only a twofold difference after normalization for the 38-kD hTFIID content. Similarly, transcriptional efficiency of both factors was comparable to that of the $38-\mathrm{kD}$ hTFIID protein produced in bacteria. The two cellular TFIID factors differ in one fundamental property: Unlike the D-TFIID activity, reactions reconstituted with the B-TFIID activity are not stimulated upon addition of the transcriptional activators GAL4-AH or Spl and only weakly by MLTF/USF. These results suggest that a component in the D-TFIID activity is critical for mediating trans-activation and that one or more of such components are not present in the B-TFIID complex. In this regard, the B-TFIID complex is similar to the activity of the recombinant $38-\mathrm{kD}$ hTFIID protein (Peterson et al. 1990; this paper). It has been proposed that the D-TFIID fraction contains coactivators that would me- 
diate the interaction of transcriptional activators with the preinitiation complex (Peterson et al. 1990; Pugh and Tjian 1990; for reviews, see Lewin 1990; Ptashne and Gann 1990). If such a coactivator activity exists it could either cofractionate fortuitously with the D-TFIID complex over two ion exchange columns or it could be an integral part of the D-TFIID complex. Support for the latter explanation comes from the recent analysis of the TFIID activity from Drosophila embryo extracts. This activity consists of a multiprotein complex of $>350 \mathrm{kD}$, containing the TFIID protein and at least six additional polypeptides (Dynlacht et al. 1991). A coactivator function must reside in one or more of these polypeptides, as addition of these polypeptides to the monomeric TFIID protein was required to restore response to a transcriptional activator. If the situation in HeLa cells is similar, then part of the differences between the D-TFIID and B-TFIID factors could be a consequence of the presence of one or more coactivators.

Two characteristics of the B-TFIID complex suggest that it does not form highly stable complexes with the TATA region of the promoter. In template commitment assays, which are dependent on the rate of exchange of the basal complex TFIIA/TFIID between a preincubated template and a newly added template, the B-TFIID activity exchanged within $1 \mathrm{~min}$ while the D-TFIID activity remained associated with the first template added. Consistent with less stable binding to the TATA region, transcription with the B-TFIID activity was more sensitive to higher concentrations of $\mathrm{KCl}$ than transcription with D-TFIID. It is possible that the high dissociation rate of the B-TFID/TFIIA/DNA indicates that the major late promoter does not represent a high-affinity binding site for B-TFIID and that a different TATA element and initiation region might bind the B-TFIID factor with higher affinity. Mutational analyses of TATA elements have provided evidence for functionally distinct processes recognizing the TATA element (Simon et al. 1988; Taylor and Kingston 1990). The observation that the majority of the $38-\mathrm{kD}$ hTFIID protein in a cellular extract is in the B-TFIID form, which is unresponsive to the action of transcriptional activators, suggests that there might be two different classes of cellular promoters. The class served by D-TFIID-type activities would be responsive to transcriptional activators of the type of GAL4-AH, Spl, and MLTF/USF. Another class would be served by B-TFIID and would be regulated by a distinct set of processes. A detailed analysis of the yeast his 3 promoter has suggested the existence of two types of initiation elements: one type that is responsive to transcriptional activators, and one that is unresponsive (Chen and Struhl 1988). The existence of two classes of promoters would allow independent regulation during growth or differentiation by changes in the levels of the different TFIID complexes. This could be accomplished by conversion of B-TFIID-type complexes into D-TFIIDtype complexes. Because the $38-\mathrm{kD}$ hTFIID protein, a TATA-binding protein, is an integral part of the two forms of TFIID activity, the different DNA-binding specificities and activities of complexes containing this pro- tein must reflect either a differential modification of this 38-kD hTFIID protein and/or a different protein composition of TFIID complexes.

\section{Materials and methods \\ Immunization and immunoblot analysis}

Glutathione $S$-transferase/human TFID fusion protein /GhIID5) was expressed in Escherichia coli strain NB42 and purified by using glutathione-Sepharose (Pharmacia) according to Ausubel et al. (1989). New Zealand rabbits were immunized subcutaneously every month with $1 \mathrm{mg}$ of G-hIID5 protein per rabbit according to Harlow and Lane (1988). Serum was collected 10-14 days after injection. Titers of antibodies directed against the fusion protein were monitored by using an ELISA assay. Sera were used for immunoblot experiments (except for Fig.1) without further purification in a $1: 500$-dilution. Affinity-purified serum (used in the experiment shown in Fig.1) was prepared by binding the serum to G-hIID5 protein immobilized on nitrocellulose and subsequently eluting the antibodies with $100 \mathrm{~mm}$ glycine- $\mathrm{HCl}(\mathrm{pH} 2.7)$. After neutralization with onetenth volume of $1 \mathrm{M}$ Tris- $\mathrm{HCl}(\mathrm{pH} 9)$, the serum was used in a $1: 20$ dilution.

Protein samples were separated in $15 \%$ SDS-polyacrylamide gels and blotted onto nitrocellulose by using the Bio-Rad miniPROTEAN II system. Protein blots were incubated with antiTFIID serum, washed three times, and developed with the ProtoBlot Western Blot AP system (Promega) according to the manufacturer's procedures.

\section{Purification of transcription factors}

Protein fractions $[\mathrm{AB}],[\mathrm{CB}]$, and $[\mathrm{DB}]$, containing the general transcription factors TFIIA, TFIIB/E/F, or TFIID, were obtained as described previously from HeLa cell extracts (Samuels et al. 1982). RNA polymerase II was purified from fresh calf thymus according to the method of Hodo and Blatti (1977) and was $\sim 50 \%$ pure as judged by silver staining of SDS-polyacrylamide gels.

Purification of the B-TFIID protein fraction began with chromatography of $2 \mathrm{~g}$ of HeLa whole-cell extract (Manley et al. 1983) on phosphocellulose (P11, Whatman) according to Samuels et al. (1982). The B fraction (560 mg protein) was adjusted to buffer A $[20 \mathrm{mM}$ HEPES- $\mathrm{KOH}$ (pH 7.9)/20\% glycerol/1 mM EDTA/l $\mathrm{mM}$ DTT/1 $\mathrm{mm}$ PMSF] plus $60 \mathrm{~mm} \mathrm{KCl}$ and applied to a 50-ml DEAE-Sepharose FF (Pharmacia) column. The flowthrough of this column (110 mg protein) contained a majority of the hTFIID protein as judged from immunoblot analysis. From this step, $1 \mu \mathrm{g} / \mathrm{ml}$ of aprotinin and $1 \mu \mathrm{g} / \mathrm{ml}$ of pepstatin (Sigma) were added to the buffers, and the DTT concentration was increased to $5 \mathrm{~mm}$. Eighty milligrams of the flowthrough fraction was adjusted to buffer $\mathrm{A} / 50 \mathrm{mM} \mathrm{KCl}$ and applied to a 15-ml Q-Sepharose FF (Pharmacia) column. The bound protein was step-eluted by buffer A plus $250 \mathrm{mM} \mathrm{KCl}$ and buffer A plus $600 \mathrm{~mm} \mathrm{KCl}$. All of the TFIID protein eluted in the $250 \mathrm{mM} \mathrm{KCl} \mathrm{step.} \mathrm{This} \mathrm{fraction} \mathrm{(13.3} \mathrm{mg} \mathrm{of} \mathrm{protein)} \mathrm{was} \mathrm{ad-}$ justed to buffer A plus $50 \mathrm{~mm} \mathrm{KCl}$ and applied to a Mono S FPLC column (Pharmacia). The column was developed with a linear gradient from 50 to $500 \mathrm{~mm} \mathrm{KCl}$ in buffer A. Human TFIID protein eluted in fractions $26-33(75-240 \mathrm{~mm} \mathrm{KCl})$ (see Fig. 2). These fractions were pooled ( $2.4 \mathrm{mg}$ of protein in $4 \mathrm{ml}$ ), adjusted to buffer A plus $100 \mathrm{mM} \mathrm{KCl}$, and used as source for B-TFIID in all experiments except for the $\mathrm{Spl}$ stimulation experiments (Fig. 7C). The Mono S pool was found to contain Spl activity and was therefore purified further on Superdex 200 PG (Pharmacia) in 
buffer A/400 mM KCl/0.01\% Triton-X 100/5 mM DTT. Fractions corresponding to a molecular mass of $300 \mathrm{kD}$ contained the TFIID protein and were adjusted to $10 \mathrm{mM} \mathrm{KPi} / 100 \mathrm{mM} \mathrm{KCl}$ $[10 \mathrm{mM} \mathrm{KPi}=10 \mathrm{~mm} \mathrm{~K}$-phosphate $(\mathrm{pH} 7.6] / 10 \%$ glycerol $/ 5 \mathrm{~mm}$ DTT) and concentrated on a $1.5-\mathrm{ml}$ hydroxyapatite (Bio-Rad) column by step-elution with subsequently $50 \mathrm{mM} \mathrm{KPi}, 250 \mathrm{~mm}$ $\mathrm{KPi}$, and $600 \mathrm{mM} \mathrm{KPi}$. The $250 \mathrm{~mm} \mathrm{KPi} \mathrm{step} \mathrm{contained} \mathrm{the} \mathrm{TFIID}$ protein and was adjusted to buffer $\mathrm{A} / 100 \mathrm{~mm} \mathrm{KCl}$ and used in the experiment of Figure 7C.

rhTFIID was expressed in E. coli BL21 by using plasmid pETHIID (Kao et al. 1990) and purified according to Peterson et al. (1990). The final heparin fraction was adjusted to $25 \mathrm{~mm}$ HEPES-KOH (pH 7.6)/0.1 mM EDTA/ $12.5 \mathrm{~mm} \mathrm{MgCl} / 10 \%$ glycerol/0.1\% NP-40/1 mM DTT/ 0.5 mM PMSF (HEMGN) plus 100 $\mathrm{mM} \mathrm{KCl}$ and loaded onto a Mono $\mathrm{S}$ column for additional purification. The column was developed with a linear 100-1000 mM $\mathrm{KCl}$ gradient in HEMGN buffer. A TFIID fraction eluting at 350 $\mathrm{mm} \mathrm{KCl}(\sim 5-10 \%$ pure) was adjusted to buffer $\mathrm{A} / 100 \mathrm{mM} \mathrm{KCl}$ and used in the transcription assays.

The MLTF preparation used was purified $\sim 90$-fold from fresh calf brain tissue (Chodosh 1988). The GAL4 derivatives were kind gifts from I. Taylor and J. Workman (Massachusetts General Hospital, Boston) and were expressed and purified from bacteria (Workman et al. 1991). Vaccinia-expressed Spl protein (20 fmoles of $S p 1 / \mu l)$ was purchased from Promega. Protein concentrations were determined by using the Bio-Rad protein assay with bovine gamma globulin (Sigma) as the standard.

\section{In vitro transcription assays}

A standard TFIID-dependent transcription reaction contained $0.3 \mu \mathrm{l}$ of calf thymus RNA polymerase II, $0.5 \mu \mathrm{l}$ of $[\mathrm{AB}], 1.5 \mu \mathrm{l}$ of [CB], and 12 units of RNasin (Promega) in a $20-\mu$ l volume. Incubation conditions were as described (Buratowski et al. 1988), with the addition of $0.1 \mathrm{mg} / \mathrm{ml}$ of BSA to stabilize proteins. Reactions were stopped, processed, and electrophoresed as described (Marciniak et al. 1990). Radioactive RNA products were quantitated with a Phosphorimager gel scanner (Molecular Dynamics, Sunnyvale, CA) and Image Quant 3.0 software.

\section{Plasmid constructions}

All DNA manipulations were performed according to standard techniques (Sambrook et al. 1989). Plasmid pG-hIID5 was obtained by in-frame insertion of a 429-bp BamHI-EcoRI fragment carrying codons $1-139$ of TFIID into pGEX-3X. The fragment was prepared by polymerase chain reaction (PCR) amplification with pGPP.21 (Peterson et al. 1990) as the template. pML $112\left(\mathrm{C}_{2} \mathrm{AT}\right)$ was constructed by insertion of the 532 -bp blunt-ended AflIII-HindIII fragment of pML(C ${ }_{2} \mathrm{AT}$ )19 (Sawadogo and Roeder 1985a) into the HincII-HindIII sites of pUC18. The construction of $\mathrm{p} \Delta \mathrm{ML}\left(\mathrm{C}_{2} \mathrm{AT}\right) 200$ (named template II) has been described (Buratowski et al. 1988). The blunted-ended XbaI-HindIII fragment of $\mathrm{pML} / \mathrm{C}_{2} \mathrm{AT}$ )19 $19-51$ (Sawadogo and Roeder 1985a) was used as vector to construct p6GALML$\left(\mathrm{C}_{2} \mathrm{AT}\right)$, pSVML $\left(\mathrm{C}_{2} \mathrm{AT}\right)$, and pHIVML $\left(\mathrm{C}_{2} \mathrm{AT}\right)$. The inserts are respectively, the 172-bp HindIII-SmaI fragment of pCZ6 (Chasman et al. 1989), a 93-bp HindIII-SmaI PCR product [with pgTat-CMV as a template [Chang and Sharp 1989)] carrying sequences $30-117$ of SV40 and a 75-bp HindIII-SmaI PCR product [with pHIV-TAR-IL2 as template (Marciniak et al. 1990)] carrying the $-116 /-45$ sequence of the human immunodeficiency virus long terminal repeat (HIV LTR). All plasmid constructs were verified by double-stranded DNA sequencing across the inserts with the Sequenase 2.0 kit (U.S. Biochemical). Plasmid DNA used in reconstituted transcription assays was purified by banding twice on $\mathrm{CsCl}$ gradients and subsequent overnight dialysis against $10 \mathrm{~mm}$ Tris- $\mathrm{HCl}(\mathrm{pH} 8.0) / 1 \mathrm{~mm}$ EDTA.

\section{Acknowledgments}

We thank R. Tjian and A. Berk for providing the hTFID cDNA clones; D. Chasman for supplying the plasmids containing the GAL4-binding sites; I. Taylor and J. Workman for providing the GAL4 proteins; S. Batson and U. Hansen for Spl purified from HeLa cells, which was used in the initial Sp1-stimulation experiments; K. Hewes and Konijn Beatrix for excellent assistance in obtaining the rabbit antisera; M. Samuels and A. Fire for preparation of the general factor fractions; L. Parent and C. Wood for expert assistance in preparing the HeLa cell extracts and help in plasmid constructions; J. Parvin and B. Shykind for help in the purification of B-TFIID; J. Parvin, T. Kristie, and J. Kjems for critical reading of the manuscript; and members of the Sharp laboratory for many thoughtful and stimulating discussions. During the time that the major portion of this work was performed H.Th.M.T. was supported by a NATO Science Fellowship administered by the Netherlands Organization for Scientific Research and was also supported by a fellowship of the Royal Netherlands Academy of Arts and Sciences. This work was also supported by U.S. Public Health Service grant PO1-CA42063, partially by Cancer Center Support (core) grant P30-CA14051 from the National Institutes of Health, and by a cooperative agreement (CDR-88030214) from the National Science Foundation to P.A.S.

The publication costs of this article were defrayed in part by payment of page charges. This article must therefore be hereby marked "advertisement" in accordance with 18 USC section 1734 solely to indicate this fact.

\section{References}

Ausubel, F.M., R. Brent, R.E. Kingston, D.D. Moore, J.G. Seidman, J.A. Smith, and K. Struhl. 1989. Current protocols in molecular biology John Wiley/Greene, New York.

Buratowski, S., S. Hahn, P.A. Sharp, and L. Guarente. 1988. Function of a yeast TATA element-binding protein in a mammalian transcription system. Nature 334: 37-42.

Buratowski, S., S. Hahn, L. Guarente, and P.A. Sharp. 1989. Five intermediate complexes in transcription initiation by RNA polymerase II. Cell 56: 549-561.

Cavallini, B., J. Huet, J.L. Plassat, A. Sentenac, J.M. Egly, and P. Chambon. 1988. A yeast activity can substitute for the HeLa cell TATA box factor. Nature 334: 77-80.

Chang D.D. and P.A. Sharp. 1989. Regulation by HIV rev depends on recognition of splice sites. Cell 59: 789-795.

Chasman, D.I., J. Leatherwood, M. Carey, M. Ptashne, and R. Kornberg. 1989. Activation of yeast polymerase II transcription by herpesvirus VP16 and GAL4 derivatives in vitro. Mol. Cell. Biol. 9: 4746-4749.

Chen, W. and K. Struhl. 1988. Saturation mutagensis of a yeast his3 "TATA element": Genetic evidence for a specific TATA-binding protein. Proc. Natl. Acad. Sci. 85: 26912695.

Chodosh, L.A. 1988. "MLTF: A human promoter-specific transcription factor." Ph.D. thesis, Massachusetts Institute of Technology, Cambridge.

Conaway, J.W., D. Reines, and R.C. Conaway. 1990. Transcription initiated by RNA polymerase II and transcription factors from liver: Cooperative action of transcription factors $\tau$ and $\epsilon$ in initial complex formation. J. Biol. Chem. 265: 75527558 . 
Conaway, J.W., J.P. Hanley, K.P. Garret, and R.C. Conaway. 1991. Transcription initiated by RNA polymerase II and transcription factors in liver: Structure and function of $\epsilon$ and т. J. Biol. Chem. 266: 7804-7811.

Davison, B.L., J.M. Egly, E.R. Mulvihill, and P. Chambon. 1983. Formation of stable preinitiation complexes between eukaryotic class B transcription factors and promoter sequences. Nature 301: 680-686.

Darst, S.A., A.M. Edwards, E.W. Kubalek, and R.G. Kornberg. 1991. Three-dimensional structure of yeast RNA polymerase II at 16 A resolution. Cell 66: 121-128.

Dynlacht, B.D., T. Hoey, and R. Tjian. 1991. Isolation of coactivators associated with the TATA-binding protein that mediate transcriptional activation. Cell 66: 563-576.

Fire, A., M. Samuels, and P.A. Sharp. 1984. Interactions between RNA polymerase II, factors, and template leading to accurate transcription. J. Biol. Chem. 259: 2509-2516.

Hahn, S., S. Buratowski, P.A. Sharp, and L. Guarente. 1989. Isolation of the gene encoding the yeast TATA binding protein TFIID: A gene identical to the SPT15 suppressor of Ty element insertions. Cell 58: 1173-1181.

Harlow, E. and D. Lane. 1988. Antibodies: A laboratory manual. Cold Spring Harbor Laboratory, Cold Spring Harbor, New York.

Hodo, H.G. and S.P. Blatti. 1977. Purification using polyethylenimine precipitation and low molecular weight subunit analysis of calf thymus and wheat germ DNA-dependent RNA polymerase II. Biochemistry 16: 2334-2343.

Hoffmann, A., E. Sinn, T. Yamamoto, J. Wang, A. Roy, M. Horikoshi, and R.G. Roeder. 1990. Highly conserved core domain and unique $\mathrm{N}$ terminus with presumptive regulatory motifs in a human TATA factor (TFIID). Nature 346: 387-390.

Horikoshi, M., C.K. Wang, H. Fujii, J.A. Cromlish, P.A.Weil, and R.G. Roeder. 1989. Cloning and structure of a yeast gene encoding a general transcription initiation factor TFIID that binds to the TATA box. Nature 341: 299-303.

Johnson, P.F. and S.L. McKnight. 1989. Eukaryotic transcriptional regulatory proteins. Annu. Rev. Biochem. 58: 799839.

Kao, C.C., P.L. Lieberman, M.C. Schmidt, Q. Zhou, R. Pei, and A.J. Berk. 1990. Cloning of a transcriptionally active human TATA binding factor. Science 248: 1646-1650.

Lin, Y.-S. and M.R. Green. 1991. Mechanism of an acidic transcriptional activator in vitro. Cell 64: 971-981.

Lewin, B. 1990. Commitment and activation at pol II promoters: A tail of protein-protein interactions. Cell 61: 11611164.

Maldonado, E., I. Ha, P. Cortes, L. Weis, and D. Reinberg. 1990. Factors involved in specific transcription by mammalian RNA polymerase II: Role of transcription factors IIA, IID and IIB during formation of a transcription-competent complex. Mol. Cell. Biol. 10: 6335-6347.

Manley, J.L., A. Fire, M. Samuels, and P.A. Sharp. 1983. In vitro transcription: Whole-cell extract. Methods Enzymol. 101: 568-582.

Marciniak, R.A., B.J. Calnan, A.D. Frankel, and P.A. Sharp. 1990. HIV-1 tat protein trans-activates transcription in vitro. Cell 63: 791-802.

Matsui, T., J. Segall, P.A. Weil, and R.G. Roeder. 1980. Multiple factors are required for accurate initiation of transcription by purified RNA polymerase II. I. Biol. Chem. 255: 1199211996.

Mitchell, P.J. and R. Tjian. 1989. Transcriptional regulation in mammalian cells by sequence-specific DNA binding proteins. Science 245: 371-378.

Nakajima, N., M. Horikoshi, and R.G. Roeder. 1988. Factors involved in specific transcription by mammalian RNA polymerase II: Purification, genetic specificity, and TATA boxpromoter interactions of TFIID. Mol. Cell. Biol. 8: 40284040.

Peterson, M.G., N. Tanese, B.F. Pugh, and R. Tjian. 1990. Functional domains and upstream activation properties of cloned human TATA binding protein. Science 248: 1625-1630.

Ptashne, M. and A.A.F. Gann. 1990. Activators and targets. Nature 346: 329-331.

Pugh, B.F. and R. Tjian. 1990. Mechanism of transcriptional activation by SP1: evidence for coactivators. Cell 61: 11871197.

Reinberg, D. and R.G. Roeder. 1987. Factors involved in specific transcription by mammalian RNA polymerase II: Purification and functional analysis of initiation factors IIB and IIE. J. Biol. Chem. 262: 3310-3321.

Reinberg, D., M. Horikoshi, and R.G. Roeder. 1987. Factors involved in specific transcription in mammalian RNA polymerase II: Functional analysis of initiation factors IIA and IID and identification of a new factor operating at sequences downstream of the initiation site. I. Biol. Chem. 262: 33223330.

Sambrook, J., E.F. Fritsch, and T. Maniatis. 1989. Molecular cloning: A laboratory manual, 2nd ed. Cold Spring Harbor Laboratory Press, Cold Spring Harbor, New York.

Samuels, M., A. Fire, and P.A. Sharp. 1982. Separation and characterization of factors mediating accurate transcription by RNA polymerase II. J. Biol. Chem. 257: 14419-14427.

Sawadogo, M. and R.G. Roeder. 1985a. Factors involved in specific transcription by human RNA polymerase II: Analysis by a rapid and quantitative in vitro assay. Proc. Natl. Acad. Sci. 82: 4394-4398.

. 1985b. Interaction of a gene-specific transcription factor with the adenovirus major late promoter upstream of the TATA box region. Cell 43: 165-175.

Sawadogo, M. and A. Sentenac. 1990. RNA polymerase B (II) and general transcription factors. Annu. Rev. Biochem. 59: 711754.

Schmidt, M.C., C.C. Kao, R. Pei, and A.J. Berk. 1989. Yeast TATA-box transcription factor gene. Proc. Natl. Acad. Sci. 86: $7785-7789$.

Simon, M.C., T.M. Fisch, B.J. Benecke, J.R. Nevins, and N. Heintz. 1988. Definition of multiple, functionally distinct TATA elements, one of which is a target in the hsp70 promoter for E1A regulation. Cell 52: 723-729.

Taylor, I.A. and R.E. Kingston. 1990. Factor substitution in a human hsp 70 gene promoter: TATA-dependent and TATAindependent interactions. Mol. Cell. Biol. 10: 165-175.

Van Dyke, M.W., M. Sawadogo, and R.G. Roeder. 1989. Stability of transcription complexes on class II genes. Mol. Cell. Biol. 9: 342-344.

Wasylyk, B. 1988. Transcription elements and factors of RNA polymerase B promoters of higher eukaryotes. CRC Crit. Rev. Biochem. 23: 77-120.

Workman, J.L., I.C.A. Taylor, and R.E. Kingston. 1991. Activation domains of stably bound GAL4 derivatives alleviate repression of promoters by nucleosomes. Cell 64: 533-544. 


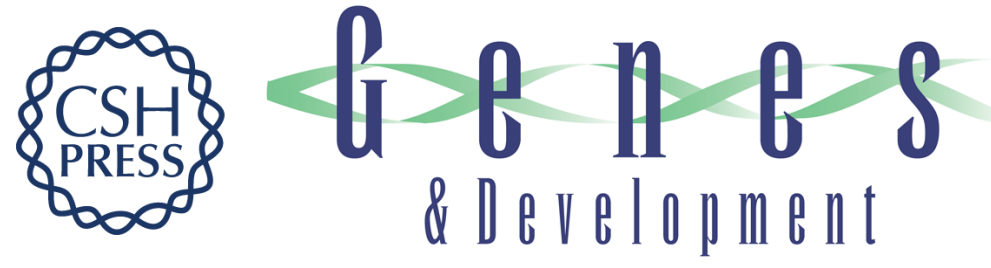

\section{The mammalian TFIID protein is present in two functionally distinct complexes.}

H T Timmers and P A Sharp

Genes Dev. 1991, 5:

Access the most recent version at doi:10.1101/gad.5.11.1946

References This article cites 41 articles, 18 of which can be accessed free at:

http://genesdev.cshlp.org/content/5/11/1946.full.html\#ref-list-1

License

Email Alerting

Service

Receive free email alerts when new articles cite this article - sign up in the box at the top right corner of the article or click here.

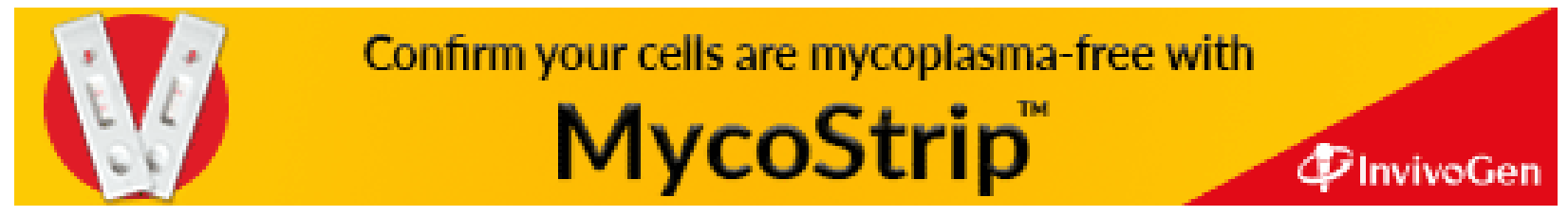

